exists in the whole field between tin and tin telluride, although the thermal effect near the tin telluride concentration was very slight. That portion of the curve lying between pure tin and tin telluride was very difficult to obtain. While only a few results are given, many other experiments were made. In many cases masses of the high melting telluride would clot together and make a good clear fusion very difficult.

The presence of the compound, SnTe, is indicated not only by the fact that the maximum point in the curve coincides with the composition demanded by the formula SnTe, but it was also identified by Tanmanu's thermal method. A line drawn through the time intervals of the separation of the two eutectics ends in each case at this composition.

Furthermore the compound is clearly indicated by the micro-structure. The alloy containing +8.28 per cent of tin shows a uniform dark field when etched with nitric acid. With increasing amonnts of tellurium more and more of the entectic shows until the composition of the pure eutectic is reached. Beyond this point crystals of tellurinm are found embedded in the eutectic. The microstructure of the alloys varying from 50 to 100 per cent. of tin is very unsatisfactory, as it is only after prolonged annealing that equilibrium is reached, and there is always much oxidation during the henting.

MASSACHTSETTS INATITTTH B

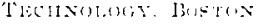

\title{
A STUDY OF THE CAUSES OF IMPURE NICKEL PLATE WITH SPEC- IAL REFERENCE TO THE IRON.
}

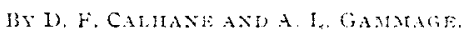

Received Inne $2 \overrightarrow{7}, 1007$

The experiments described in the following article were performed for the purpose of ascertaining the amount of iron present in nickel plate and also to study the conditions that infinence the deposition of this undesirable impurity. In the course of this wotk a point of considerable iuterest was met with and further investigated as detailed later.

It is a fact of everyday experience that nickel plate rusts on any prolonged exposure to moisture, and this rusting is pronounced to be due to small amounts of iron contained in the plate and coming from the solution during the plating process. This impurity may be conceived as constituting with the nickel a series of galvanic couples that cause rapid rusting in the presence of moisture and carbon dioxide of the air.

The universal method of plating on a commercial scale is to suspend a bar compounded of nickel and iron as anode in a bath of the double salt, nickel-ammonium sulphate, the article to be plated constituting the other pole or cathode.

The presence of the iron in the anode is due to the fact that pure nickel is not corroded rapidly enough to furrish the necessary nickel to 
the solution. Iron is the cheapest material and has a solution tension enough greater than nickel to make it effective for the end in view.

The anode bars as sold to the platers are guaranteed to be over 90 per cent. nickel. The double salt of nickel-ammonium sulphate is dissolved in hot water and diluted up to $6^{\circ}$ to $8^{\circ}$ Beatumé, giving a nearly saturated solution. In winter the concentration is run as low as $5^{\circ}$ Beaumé, to prevent the salt from crystallizing out.

During the plating, as the anodes are corroded a brown sludge of basic iron salt is formed on the surface and must be brushed off every day and the accumulated deposit cleaned from the tanks weekly.

To conclusively prove the fact that iron is present in nickel plate as ordinarily deposited, a sheet of platinum was plated at a local establishment, and the deposit, about one gram, removed with hydrochloric acid and a qualitative analysis made, which showed small anounts of iron.

Attention was next turned to finding out how the iron came to be in the nickel plate. This would result either from mechanical occlusion, deposition by the current or a combination of both causes.

Portions of nickel anode bars that had been used in actual work in two different establishments were procured, and thoroughly cleaned with water and acid until only the nickel showed. Small samples of these were taken and analyses made for their iron content. Portions of four different bars were thus used. A qualitative analysis showed nickel, iron and small amounts of carbon and silicon.

The samples were analysed for iron by the basic acetate process ${ }^{1}$ and gave 7.59 and 7.56 per cent. of iron. Two other samples were analyzed for iron by the ferric hydroxide method as is usual in commercial analysis, and gave 7.53 and 7.52 per cent. of iron. The vickel in these latter two solutions was determined by electrolysis, ${ }^{2}$ using the customary procedure, and gave 91.96 and 92.01 per cent. of nickel. The remaining one-half per cent. was composed mainly of silicon and traces of other impurities, from which, however, no test for cobalt was obtained.

A qualitative analysis of the nickel anmonium sulphate showed as impurities traces of iron, sodium and organic matter.

A solution of the ordinary nickel salt was made up to a strength of 250 grams in three liters and this placed in each of two glass battery jars. Small pieces of the commercial anodes containing about 8 per cent. iron, were drilled and suspended by wires in the solution. Two anodes were used in each jar.

For cathodes, strips and spirals of platinum were used, so that the deposit could be stripped off. As it was observed that the shape of the

1 Treadwell Analytical Chemistry, p. 123.

2 Ibid., p. I 2. 
cathode had some influence on the nature of the deposit, the plates and spirals were used to better study this particular point.

In the first instance, two platinum strips about 2 inches wide and 4 inches long were plated at the works of a local establishment, and on analysis of the deposit were found to contain 0.096 and 0.080 per cent. of iron. These results show a very small portion of iron, but yet enough to constitute an appreciable impurity, and account for the rusting of plated articles.

Experiments in the laboratory were directed towards the study of variations in conditions and their effect on the iron impurity. Platinum strips were used of a size about $9 \times 4.5 \mathrm{~cm}$, and which weighed about 8 grams each.

A current density of 0.04 ampère per sq. cm. was at first employed, or 2 ampères current for the total surface immersed.

In ove hour a deposit of 1.940 grans was obtained. The theoretical ampère hour efficiency for nickel is 1.094 grams. This gives a current efficiency of 88.20 per cent. An analysis of the deposit for iron was made anci gave 0.147 per cent. The deposit obtained in this experiment was bright, but had begun to peel, showing either a too high current density or unclean surface. The platinum was subsequently cleaned with fine sand, sodium hydroxide and hydrochloric acid or potassinu cyanide.

In the next experiment two baths were run in series, with all the conditions the same in one as in the other except that one of the solutions was stirred by a rotator turning i 30 revolutions per minute. The current was 0.75 ampère. An exanination of the films of deposited nickel at the end of the experiment showed that each was inclined to peel and the one deposited in the solution that was stirred looked the better of the two. In one hour the plate from the solution that was not stirred had received a deposit of $0.7+25$ gram of nickel, showing a current efficiency of 90.48 per cent. The plate from the stirred solution had received $0.7402 \mathrm{~g}$ ram of nickel, showing practically the same efficiency.

Here, both cathodes were stationary and one solution stirred, which had practically no effect on the current efficiency in nickel. As will be shown later, a widely different result is the case when the cathodes are rotated.

An analysis for irou in the deposits obtained in the last experiment was made and gave 0.13 per cent. for the still solution and 0.36 per cent. for the stirred solution. As will be seen from the previous figures, the agitation of the solution greatly increases the iron impurity of the nickel deposit, showing large amounts of mechanical occlusion.

The current previously used was evidently too great, and a duplicate of the experiment last described was carried out using 0.2 ampère 
current. This gave a firmly adhering deposit with practically the same amounts of iron impurity as last detailed.

In the next experiment the cathode in one case was stationary, and in the other was rotated at I 30 turns per minute. The platinum sheets were used as before. The results here in one respect were surprising. After two and one-half hours' time with 0 .I ampère current, there was deposited on the stationary cathode 0.2506 gram of nickel and on the rotated one 0.0380 . The still deposit was bright and firmly adherent. The other one was dark and less firm. This corresponded to an efficiency of $9 \mathrm{I}$ per cent. and $\mathrm{I} 2$ per cent. in nickel in the respective cases.

A duplicate of the above trial was made under exactly the same conditions, the current acting for two hours. The still electrode received 0.2080 gram deposit, corresponding to an efficiency of 94 per cent., and the one that was rotated, a deposit of $0.0354 \mathrm{gram}$, answering to an efficiency of 16 per cent. The deposits of the last two experiments were analyzed for iron content and gave for the still cathode $O$.I I and 0 . Io per cent. and for the rotating cathode 0.54 and 0.56 per cent.

With such small deposits of iron these figures agree very we!l. The striking deficiency of nickel deposit in the case of the rotated cathode is again to be noted.

With the same speed of rotation and a current of 0.5 ampère, a run of an hour's duration was made to see if the rotated cathode would take on more nickel with the larger current. On the still cathode the deposit was 0.4945 gram, corresponding to an efficiency of 90 per cent. The rotated cathode received a deposit of 0.0659 gram, answering to an efficiency of 12 per cent.

During the previous experiments, it was noticed that although the electrolyte when the start was made was perfectly clear, it grew slightly cloudy during the time of the experiment. This led to the idea that some of the iron impurity might be kept out of the nickel deposit by surrounding the anodes with some filtering medium. Canvas bags were made, and in these pockets each anode was hung. With this arrangement, and freshly prepared solutions of nickel salt, 0.1 ampère in three hours deposited 0.2928 gram on the still cathode, and 0.0594 gram on the cathode rotated at 260 turns per minute. This corresponds to current efficiencies of 90 per cent. and 18 per cent. respectively.

The analysis for iron gave 0.05 and 0.75 per cent. respectively. Checks on these results under the same experimental conditions gave 0.07 and 0.80 per cent. of iron respectively.

As it was found that the platinum strips would not stand a rotation higher than 260 turns per minute, spirais were used for the faster speeds. In stripping the nickel from the platinum, the deposits on the still cathodes dissolved with considerable difficulty in the hydrochloric acid, 
while the deposits from the cathodes that were rotated were in many instances dark colored and dissolved very readily, as though an oxide might be present. The bags added no appreciable resistance to the bath. An experiment was tried without the bags around the anodes, rotating one spiral as cathode at 260 turns per minute and another as cathode at I04 I turns per minute. After four and one-half hours the deposits were $0.34 \mathrm{I} 5 \mathrm{gram}$ on the 260 speed cathode and $0.27 \mathrm{I} 6 \mathrm{gram}$ on the IOH speed cathode. This corresponds respectively to current efficiencies of 69 and 55 per cent. The current used was 0.1 ampère. The higher speed here appears to cut down the effieiency in a marked degree. The deposits in the two cases were analyzed for the iron present and gave 0.70 and $0.7+$ per cent. The marked increase in the iron impurity without the bags at this high rotation is noticeable, anch also the near agreement in results from widely differing speeds.

Another experiment was tried with the bags, under the same conditions as before. In three hours, 0.2315 gram of nickel was deposited on the one rotated at 260 turns, and $0.1820 \mathrm{gr}$. on the one turning at ro4I revolutions. This corresponds to current efficiencies of 70 and 55 per cent. respectively, checking in this respect the previous figures. The ceposits were good, did not peel, and the coating, on the spiral revolved at I04 I turns, was as bright and smooth as if buffed. The analyses for iron gave 0.07 and 0.0 S per cent. It was found impossible to rotate the spirals faster than 104 t tums per minute, so for higher speeds a small platinum electrode, composed of small pieces of the metal welded to a thick wire, was employed.

In the next experinent one spiral rotated at 519 turns and the other electrocle at 2160 turns; in this instance the electrolyte was in a platinum dish covered with isinglass. The spiral deposit was bright but the other electrode turning at the higher speed, was dark colored. In the one case at 5 I 9 turns, the deposit was 0.2135 gram, and at the 2160 speed the deposit was o.r 34 gram, corresponding to efficiencies of 65 and to per cent. respectively. Analyses for iron gare 0.07 per cent. in each case.

These results with the bags as the filtering media, and without them, show conclusirely that at least 0.07 per cent. of iron comes by primary deposition or deionization. Further, the faster the cathodes are rotated the less the current efficiency in nickel. This was again strikingly shown by an experiment using $0 . I$ ampere current for three hours through three cells in series, in one of which the cathodes rotated at 260 turns, in another at IO4 I turns, and in the third where a platinum strip was used as anode instead of compound nickel, the cathode was revolving at 2160 turns. The deposits were $0.2310 \mathrm{gram}, 0.18 \mathrm{II}$ gram, and 
o. 1228 gram respectively, showing current efficiencies of 70 per cent., 55 per cent. and 39 per cent. in the several cases.

The idea occurred to us that the marked current deficiencies might possibly be due to sluffing or peeling off of the deposited nickel from the rotating cathode.

In the next experiment the cathodes were rotated inside porous battery jars, new, and carefully cleaned beforehand. Inside of one a platinum plate was rotated at 260 turns, and within a second, a spiral rotated at 260 turns. The current was 0.2 ampère for three hours. The deposit on the plate was 0.2200 gram, and on the spiral $0.43 \mathrm{r} 3$ gram answering the current efficiencies of 33 and 65 per cent. respectively.

After the experiment the solutions from the cathode compartments were carefully filtered and the filters examined for nickel. Less than 0.0005 gram was detected. This result appears to preclude the possibility of any marked loss of nickel from the electrode.

Analyses for iron on the above deposits showed 0.08 and 0.07 percent. respectively. Duplicates of the above experiment showed 0.06 and 0.07 per cent. of iron in the two cases. In another experiment, duplicating the previous ones with jars, a spiral was rotated at I04I turns and another remained stationary, a copper voltameter was in series with the two cells to very exactly measure the current. A current of $O . I$ ampère as shown by the ammeter was sent through for three hours. On the still cathode the deposit was $0.3202 \mathrm{gram}$ of nickel, and on the rotated cathode the nickel weighed 0.169 I gram.

In the voltameter 0.3704 gram of copper was deposited. This gave an exact calculation for current of 0.1044 ampère. The current efficiency in nickel deposited is respectively 93.54 and 49.41 per cent. This restult shows conclusively the marked decrease in current efficiency as measured by the nickel deposited due to the rotation of the cathode. This deficiency is proportional to the speed of rotation.

The analyses for iron in the deposits of the above experiment showed 0.043 per cent. in the deposit on the still cathode and 0.08 per cent. in the deposit on the rotated one. A check on the rotated cathode gave a current efficiency of $5 \mathrm{I}$ and 0.08 per cent. of iron.

Using the ordinary compound anode containing about 7.5 per cent. of iron, the amount of this element present in nickel plate will arerage about 0.10 to 0.14 per cent.

If the electrolyte is stirred or the electrodes rotated the amount of the iron impurity increases very considerably.

If the anodes are surrounded by bags or any suitable filtering medium, as has been shown in the foregoing experiments, the amount of the iron impurity is cut down about one half.

It appears that iron to the extent of 0.04 to 0.05 per cent. will appear 
in the nickel plate in spite of filtering septa, and is probably the result of primary deposition by the current.

The use of bags over the anodes seems desirable, as they do not appreciably raise the voltage, and they keep the bath much cleaner and decrease the iron impurity in the nickel deposit by about one-half.

The surprising deficiency of the nickel deposit measured in current used, when the cathode is rotated, is interesting and will be further investigated with other metals and their compounds. This deficiency has been found to depend essentially on the speed of rotation, increasing as the speed of rotation increases. Until further investigation no attempted explanation of this fact will be advanced.

The total avoidance of smali amounts of iron in the nickel plate does not seem possible with the anodes at present used in technical work.

The problem of the pure nickel anode with an effective corroding electrolyte will be further investigated in this laboratory.

IABORATORI OF AMPIED ELLETRO-CHMMSTRY,

Worcester Folytechnic Institute.

\section{POTASSIUM AMMONOZINCATE.}

A RHPRESLNTATIVE OF A NEW CIASS OF COMPOLNDS.

BY ITIWARD C. FRANKIIX.

Received June 25. 1907 .

Following the program of developing the ammonia system of acids, bases and salts inaugurated in this laboratory, Mr. F. F. Fitzgerald ${ }^{1}$ has succeeded in preparing an ammonia anlogue of the potassium zincate which is geverally" assumed to be formed when metallic zinc, zinc oxide or zinc hydroxide is dissolved in an aqueons solution of potassium hydroxide. He obtained this ammono salt, to which he gave the formula, $\mathrm{Zn}(\mathrm{NHK})_{2} .2 \mathrm{NH}_{3}$, by the action of an ammonia solution of potassium anide on metallic zinc and on zinc amide in accordance with the equations:

$$
\begin{aligned}
& \mathrm{Zn}+2 \mathrm{KNH}_{2}+\mathrm{Am}_{\mathrm{m}}=\mathrm{Zn}(\mathrm{NHK})_{2} \cdot 2 \mathrm{NH}_{3}, \cdots \mathrm{H}_{2}, \\
& \mathrm{Zn}\left(\mathrm{NH}_{2}\right)_{2}+2 \mathrm{KNH}=\mathrm{Zn}(\mathrm{NHK})_{2} .2 \mathrm{NH}_{3},
\end{aligned}
$$

which are obvionsly analogous to the reactions whereby Comey and Jackson ${ }^{3}$ prepared the compounds, $\mathrm{Zn}_{3} \mathrm{O}_{6} \mathrm{Na}_{4} \mathrm{H}_{2}$. ${ }_{9} \mathrm{H}_{2} \mathrm{O}$ and $\left(\mathrm{ZnO}_{2} \mathrm{NaH}\right)_{2} \cdot 7 \mathrm{H}_{2} \mathrm{O}$, and Förster and Gïnther the componnd to which they gave the formula, $(\mathrm{OH}) \mathrm{Zn}(\mathrm{ONa}) \cdot 3 \mathrm{H}_{2} \mathrm{O}^{5}$.

Unfortunately Fitzgerald's work was brought to a sudden end by the great earthquake before entirely satisfactory evidence as to the compo-

1 This Journa1, 29,656 .

2 Abegg's Handb, anorg. Chem., 2.2, $33^{\mathrm{S}}$.

'An. Ch. J., 11, I 45 .

4 . Eilektrochem., 6, 30I.

5 This latter compound, it should be noted, is probably identical with the compound, $\left(\mathrm{Z}_{11} \mathrm{O}_{2} \mathrm{NaH}\right)_{2} \cdot 7 \mathrm{H}_{2} \mathrm{O}$, of Comey and Jackson, inasmuch as the two products differ in composition by half a molecule of water only. 